\title{
Heart of Yellow Bellied Sea Snake (Hydrophis platurus): A Gross Morphological Study
}

\author{
Naveen Jonnalagadda, M.P.S. Tomar*, Satish Putluru, Dharani Palanisamy, \\ Sunil Akula and Venakata P. Tanguturi
}

\author{
Department of Veterinary Anatomy, College of Veterinary Science, Proddatur (Sri \\ Venkateswara Veterinary University, Tirupati) - Kadapa (Andhra Pradesh) - 516360, India
}

*Corresponding author

\section{A B S T R A C T}

\begin{tabular}{|c|}
\hline Keywords \\
\hline $\begin{array}{l}\text { Aorta, Atrium, } \\
\text { Heart, Sea snake, } \\
\text { Sinus venosus, } \\
\text { Ventricle }\end{array}$ \\
\hline Article Info \\
\hline $\begin{array}{l}\text { Accepted: } \\
26 \text { February } 2018 \\
\text { Available Online: } \\
10 \text { March } 2018\end{array}$ \\
\hline
\end{tabular}

\section{Introduction}

In many cases, the structural-functional features of the reptilian heart provide adaptive plasticity, allowing for the ecological and behavioral diversity seen. As a result, variation may surface in clinical measures of cardiac performance (Wyneken, 2009). The yellow bellied sea snake is member of subfamily Hydrophiinae and has a wide range of habitat and often seen in ocean drift lines. The habitat includes Indo-pacific which extends to Costa Rica, southern California and northern Peru and they require $16-18^{\circ} \mathrm{C}$ water for optimum survival and propagation. Due to a wide range of distribution it lacks of dispersal barriers and considered as species of least concern in IUCN red list, 2012. Contrary to past belief this species require fresh water to survive and drinks precipitation over the surface of sea water. Sometimes they are trapped in the fisherman's net and brought to the beaches along with the fishes. Individual of this species are highly poisonous with LD50 $=0.067 \mathrm{mg} / \mathrm{kg}$ for subcutaneous route and the yield per bite is 1.0-4.0 $\mathrm{mg}$. (www.seanthomas.net). Generally they are considered as docile but are deadly poisonous if exaggerated. They survive in the marine water and for that the salt excreting gland 
present sublingually is to be considered of great importance. The venom is neurotoxic but its bite does not pose any threat to humans but Due to fear to the snake, the people are killing them when they are cited in the fishermen net (www.animalspot.net). This species has a wide variety of adaptation which makes them able to survive in its habitat. Thus the present study was planned to observe various specific characteristic features on various organ systems of yellow bellied sea snake. In this regard, the first observations were recorded on the heart of yellow bellied sea snake.

\section{Materials and Methods}

The present study was conducted on the single specimen of heart of yellow bellied sea snake procured from Nellore beach, Andhra Pradesh. The snake was died due to injuries by the fisherman's net during fishing activities. It was collected in $10 \%$ neutral buffered formalin. The gross parameters of the heart were observed and the morphometry was done with non-elastic thread and a scale with calibrations in millimeters.

\section{Results and Discussion}

The heart of yellow bellied sea snake was located between $28-35^{\text {th }}$ rib in oblique direction in the pericardial sac (Fig. 1A and B). The pericardium was thin fibrous structure enclosing the heart. The heart was 3 chambered which showed a well-developed inter-atrial septum and muscular ridge like inter-ventricular septum. Similar observations were recorded by Gillett et al., (2017) in Australian sea snake. It was valentine heart shaped in outline and showed a wide base and pointed apex. The apex did not show any gubernaculum cordis which was found similar to the reports of Schilliger in snakes.

The base was wide and comprised of left and right atria whereas the apex was formed by ventricle. The atrial wall was membranous. Similar reports were observed by Mc Arthur et al., (2004), Huchzermeyer (2003), Mader (2006) and Jensen et al., (2010a \& b). Right atrium was quadrangular in outline and overhang on the right side of the ventricle thus it was covering approximately $3 / 4^{\text {th }}$ of right surface of the ventricle. It had 3 openings viz. one for anterior vena cava, second for posterior vena cava and third for right subchamber of ventricle. The present observations were found in accordance with the report of Mader (2006) in snakes and Jensen et al., (2010b) in python.

The Anterior and posterior venacava were confluence to make a common dilated cavity called sinus venosus which opened into the cavity of the right atrium. The presence of sinus venosus was also observed by Jensen $e t$ al., (2010a \& b) in python heart and rattle snake and Mader (2006) in other reptiles.

The opening of posterior vena cava was slit like and it was guarded by membranous valves (Fig. 4) as also mentioned by Jensen et al., (2014) in yellow anaconda. The jugular vein joined the anterior vena cava at the latter's opening in to the sinus venosus. Similarly Jensen et al., (2010a) mentioned that the sinus venosus was formed by the confluence of anterior vena cava, jugular vein and the posterior vena cava in the heart of rattle snake. No valve could be observed at the opening of anterior vana cava and the jugular vein. Both the caval veins ran along the right border of the heart.

The cavity of right atrium was smaller which tallied with the reports of Mc Arthur et al., (2004).

The left atrium was prismatic with dorsally located tapering apex with thinner wall. Mc Arthur et al., (2004) also reported about the thin walled left atrium in turtles. 
Fig.1 (A-D) Showing the heart in yellow bellied sea snake
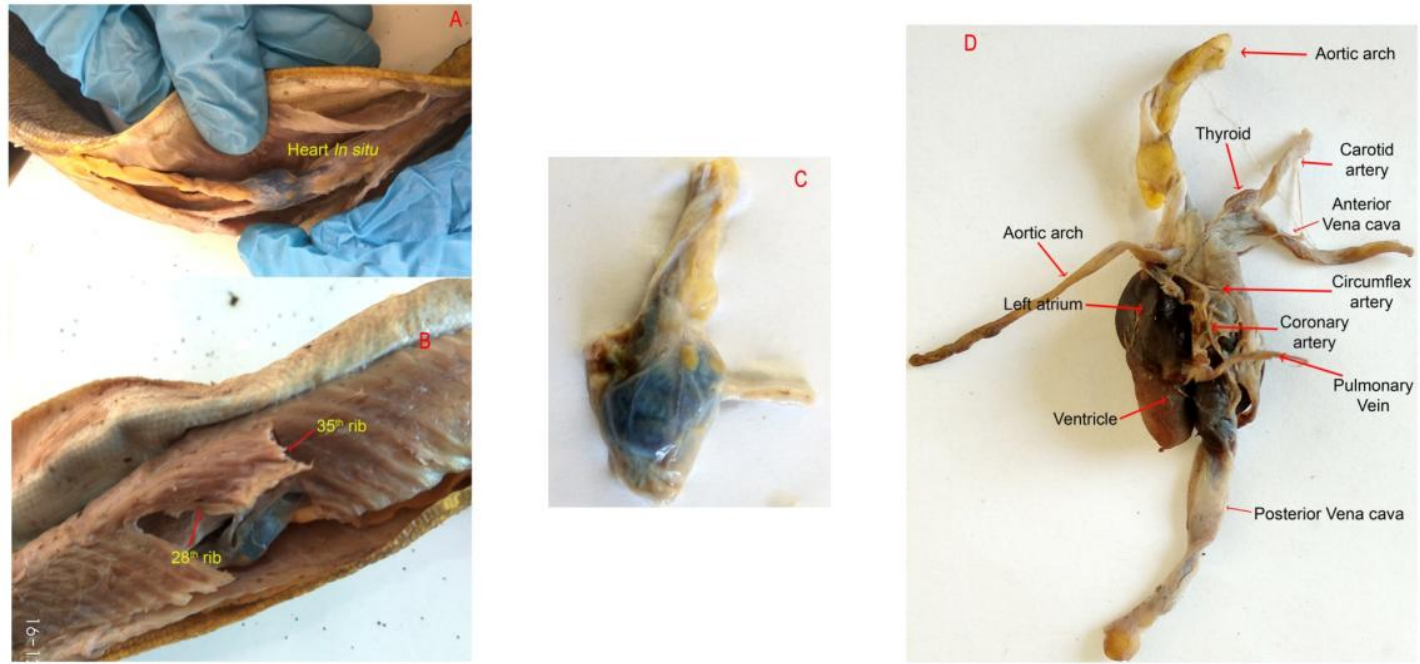

A. The location of heart in situ

B. The topography of the heart

C. Heart along with its pericardium

D. Heart and its associated vessels and structures

Fig.2 (A-B) Showing the interior of the heart of yellow bellied sea snake
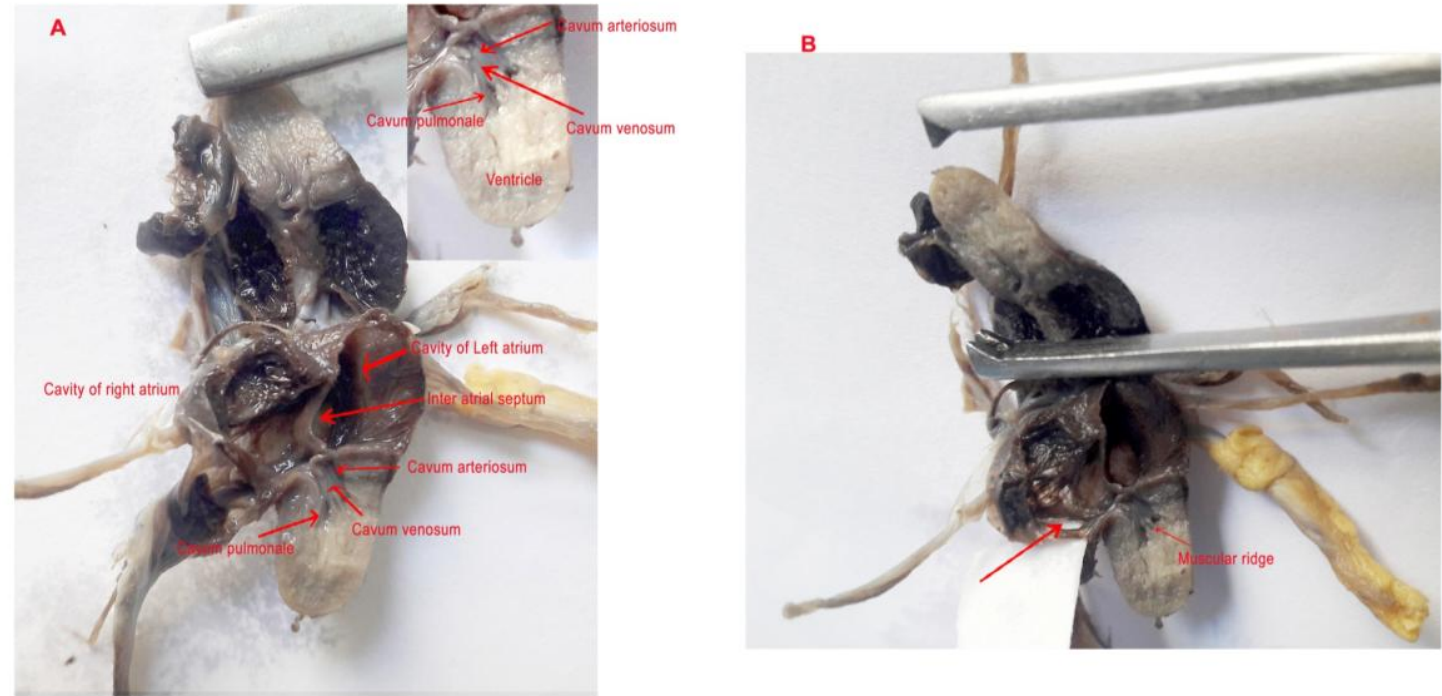

A. Cavities of right and left atrium, inter atrial septum, cavity of ventricle (divided in to cavum pulmonale, cavum venosum and cavum arteriosum)

B. The valves present on the opening of posterior vena cava in to the sinus venosus (red arrow) and incomplete ventricular septum in the form of muscular ridge.

The pulmonary vein was single and present on the postero-dorsal aspect of the left atrium and it ran over the posterior vena cava which was in accordance to the reports of Jensen et al., (2010a) in rattle snake, and it crossed over the vena cava however, Mc Arthur et al., (2004) observed separate right and left pulmonary vein in turtles. After crossing, it was divided into two branches. Morphometrically the right atrium was 
$1.20 \mathrm{~cm}$ in length and $0.90 \mathrm{~cm}$ in width, whereas left atrium was $0.80 \mathrm{~cm}$ in length and $0.60 \mathrm{~cm}$ in width. The length width index for the right and left atria was 1.33.

The atrioventricular canal was situated slightly towards the left of the midline of the heart and was divided into a right cavum pulmonale and left cavum arteriosum of which the right one was slightly larger and longer than the left. The cavum venosum was present in between the cavum pulmonale and the cavum arteriosum. Present finding was similar to the quotes of Jensen et al., (2014) in lizards and snake.

The Ventricle was elongated triangle muscular compartment with ventrally located apex. Internally the cavity of ventricle was divided into two partial chambers dorsally by a muscular ridge and ventrally by an incomplete inter ventricular septum (Fig. 3). The presence of incomplete partition was in accordance with the reports of Jensen et al., (2014) in reptiles and Gillett et al., (2017) in Australian sea snakes. This observation tallied the reports of Jensen et al., (2010b) in python heart. This muscular ridge was incomplete towards the apex of the heart. Thus enabled passage of the blood from one chamber to another chamber (enables mixing of oxygenated blood with deoxygenated blood). Similar reports were mentioned by Mc Arthur et al., (2004), Huchzermeyer (2003) and Mader (2006).

The wall of ventricle was thick but had more thickness towards right side. The pulmonary aorta was originated from right of ventricle and it ran between right and left atrium and at the base of heart it was divided into right and left pulmonary arteries as also reported by Mc Arthur et al., (2004), Huchzermeyer (2003) and Mader (2006). Morphometrically ventricle was $1.0 \mathrm{~cm}$ long and $0.60 \mathrm{~cm}$ wide with the length width index of 1.67 whereas
Jensen et al., (2010b) observed length width index as 1.30 in python heart.

Two aortic branches were originated from both the segments of ventricle and united together to form a single aorta which at base of heart divided into two arches. From ascending aorta, coronary artery was originated which after giving its first branch to the aorta, gave a collateral branch - left circumflex artery near the base of left atrium. Later the coronary artery continued in left longitudinal groove. Right coronary artery was small and gave supply to left atrium only (Fig. 2). Similar observations were made by Jensen et al., (2010b) in python.

\section{References}

Gillett, A. K., Ploeg, R., Flint, M., and Mills, P. C. 2017. Postmortem examination of Australian sea snakes (Hydrophiinae): Anatomy and common pathologic conditions. Journal of Veterinary Diagnostic Investigation. 1-19.

Huchzermeyer, E. W., 2003. Crocodiles: Biology, husbandry and diseases. CAB international publishing, Cambridge USA. Pp. 22-23.

Jensen, B., Abe, A. S., Andrade, D. V., Nyengaard., J. R., and Wang, T. 2010a. The heart of the South American Rattlesnake (Crotalus durissus). Journal of morphology. 271: 1066-1077.

Jensen, B., Moorman, A. F. M., and Wang T. 2014. Structure and function of the hearts of lizards and snakes. Biological Reviews. 89: 302-336.

Jensen, B., Nyengaard, J. R., Pedersen, M., and Wang T. 2010b. Anatomy of python heart. Anatomical Science International. 85: 194-203.

Mader, D. R. 2006. Reptile medicine and surgery. W B Saundars company, Philadelphia. Pp. 39-46. 
McArthur, S., Wilkins, R., and Meyer, J. 2004. Medicine and surgery of tortoises and turtles. Blackwell publishing Oxford UK. Pp. 40.

Schilliger, L. H., Reptile Cardiology (file available at https://fvl.vfu.cz/information-aboutfaculty/sections-departments/avian-andexotic-animal-clinic/pedagogical- activity/diseases-of-exoticpet/masterclas_schilligerxcardiologyx.p df)

www.animalspot.net www.seanthomas.net

Wyneken, J., 2009. Normal reptile heart morphology and function. Veterinary Clinics of North America Exotic Animal Practice. 12(1):51-63.

\section{How to cite this article:}

Naveen Jonnalagadda, M.P.S. Tomar, Satish Putluru, Dharani Palanisamy, Sunil Akula and Venakata P. Tanguturi. 2018. Heart of Yellow Bellied Sea Snake (Hydrophis platurus): A Gross Morphological Study. Int.J.Curr.Microbiol.App.Sci. 7(03): 3192-3196. doi: https://doi.org/10.20546/ijcmas.2018.703.369 